\title{
Métodos de superação de dormência em sementes de Macroptilium lathyroides e influência da luz e da temperatura na germinação
}

\author{
Methods of overcoming seed dormancy in Macroptilium lathyroides and influence \\ of light and temperature on germination
}

\author{
Marcia Souza Almeida Silva ${ }^{1}\left({ }^{*}\right)$ \\ Oscar Mitsuo Yamashita² \\ Germani Concenco ${ }^{3}$ \\ Maicon Douglas Arenas Souza ${ }^{4}$ \\ Cleverson Rodrigues ${ }^{5}$
}

\section{Resumo}

Estudos sobre as exigências ambientais para germinação das sementes de espécies de plantas invasoras é de fundamental importância para o conhecimento do seu comportamento ecológico no campo. Dois experimentos distintos e, em sequência, foram conduzidos em duas etapas objetivando-se estudar os efeitos de diferentes métodos de quebra de dormência das sementes de Macroptilium latbyroides e sua germinação em função de luz e temperatura. No primeiro experimento, os tratamentos constituíram-se pelos seguintes métodos de quebra de dormência: escarificação mecânica com lixa por 05, 10 e 15 minutos; escarificação química através da imersão em ácido sulfúrico por 05, 10 e 20 minutos; imersão em água quente à temperatura de $75^{\circ} \mathrm{C}$ por 05,10 e 15 minutos; escarificação com choque térmico por 05, 10 e 15 minutos; escarificação por ação do calor em temperatura de $65^{\circ} \mathrm{C}$ por 02,04 e 06 horas; além da testemunha. As sementes germinadas foram contadas diariamente e, no final de 10 dias, determinou-se a \% de germinação, o IVG, parte aérea e comprimento da raiz. Na segunda etapa, as sementes foram submetidas à presença e ausência de luz nas temperaturas constantes de 20,25, 30 C. Determinou-se germinação, IVG, parte aérea, comprimento da raiz e

1 Me.; Biodiversidade e Agroecossistemas Amazônicos; Universidade do Estado de Mato Grosso, UNEMAT, Brasil; Cursando último semestre de segunda licenciatura em Geografia pelo Instituto Pró-Minas; Endeereço: R. Maria Matos, no 345 - Loja 05 - Centro, Cel. Fabriciano - MG, CEP: 35170-111; E-mail: marcya_biologia@hotmail.com (*) Autor para correspondências

2 Dr.; Agricultura Tropical; Universidade Federal de Mato Grosso, UFMT, Brasil; Professor efetivo adjunto Doutor classe 2C da Universidade do Estado de Mato Grosso; Endereço: Universidade do Estado de Mato Grosso, Campus Universitário de Alta Floresta, Alta Floresta. Avenida Perimetral Rogério Silva, Jardim Flamboyant. CEP: 78580-000 Alta Floresta, MT - Brasil; E-mail: yama@unemat.br

3 Dr.; Fitotecnia; Universidade Federal de Viçosa, UFV, Brasil; Professor Permanente do Curso de Pós-Graduação em Fisiologia Vegetal da Universidade Federal de Pelotas; Endereço: Embrapa Clima Temperado. Rodovia BR-392, Km 78, 9o Distrito, Monte Bonito, Centro. CEP: 96010971 - Pelotas, RS - Brasil; E-mail: germani.concenco@embrapa.br

4 Doutorando; Ciências Biológicas; Universidade Federal do Rio de Janeiro, UFRJ, Brasil; Aluno de Doutorado em Ciências Biológicas (Botânica) da Universidade Federal do Rio de Janeiro - UFRJ; Endereço: Universidade Federal do Rio de Janeiro, Museu Nacional. Horto Botânico - Quinta da Boa Vista, s/n - Laboratório de Biologia Floral e Reprodutiva, São Cristóvão. CEP: 20940040 - Rio de Janeiro, RJ - Brasil; E-mail: maicondouglas_biologia@hotmail.com

5 Me; Biodiversidade e Agroecossistemas Amazônicos; Universidade do Estado de Mato Grosso, UNEMAT, Brasil; Professor substituto no Instituto Federal de Mato Grosso - campus de Alta Floresta, no ensino dos curso técnico em Agropecuária e Superior Bacharelado em Zootecnia e Professor horista da Faculdade de Alta Floresta no Curso Tecnologo em Gestao do Agronegocio; Endereço: Instituto Federal de Educação Ciência e Tecnologia de Mato Grosso, IFMT Campus Alta Floresta. ROD. MT - 208, RODOVIA. CEP: 78580000 - Alta Floresta, MT - Brasil; E-mail: cleverson-ro@hotmail.com

\begin{tabular}{llllll}
\hline Ambiência & Guarapuava (PR) & v.l4 n.3 & p.579-593 & Set/Dez 2018 & ISSN 1808 - 025I
\end{tabular}


massa seca. A escarificação química através da imersão em ácido sulfúrico durante 20 minutos e a mecânica com lixa no 120 durante 01,02 e 04 minutos foram os métodos mais eficientes. A espécie foi classificada como fotoblástica "preferencial" e a germinação respondeu positivamente a todas as temperaturas testadas.

Palavras-chave: ácido sulfúrico; calor; lixa; luminosidade.

\section{Abstract}

Studies on the environmental requirements for seed germination of weeds are of fundamental importance for the knowledge of their ecological behavior in the field. Two separate and sequential experiments were conducted in two stages aiming to study the effects of different methods of dormancy breaking of Macroptilium latbyroides seeds and their germination as a function of light and temperature. In the first experiment, treatments consisting of the following methods of breaking dormancy: mechanical scarification with sandpaper for 5, 10 and 15 minutes; chemical scarification by immersion in sulfuric acid for 5, 10 and 20 minutes; immersion in hot water at temperature of $75^{\circ} \mathrm{C}$ for 05,10 and 15 minutes; scarification with heat shock for 05 , 10 and 15 minutes; scarification by the action of the heat in temperature of $65^{\circ} \mathrm{C}$ by 02 , 04 and 06 hours; besides the witness. The germinated seeds were counted daily and, at the end of 10 days, the germination, IVG, aerial part and root length were determined. In the second stage, the seeds were submitted to the presence and absence of light at constant temperatures of $20,25,30^{\circ} \mathrm{C}$. Germination, IVG, aerial part, root length and dry mass were determined. Chemical scarification by immersion in sulfuric acid for 20 minutes and mechanics with No. 120 sandpaper for 01, 02 and 04 minutes were the most efficient methods. The species was classified as "preferential" photoblast and germination responded positively to all tested temperatures.

Key words: sulfuric acid; heat; sandpaper; luminosity.

\section{Introdução}

A espécie Macroptilium lathyroides, vulgarmente conhecida como figo-de-pombo, feijãodos-arrozais ou feijão-de-rola, é uma leguminosa com grande capacidade de fixação biológica de nitrogênio, utilizada como adubo verde em algumas regiões do Brasil (LORENZI, 2000). É uma planta anual, ereta, ocasionalmente ascendente, herbácea, ramificada, de caule glabro e esparsamente sérico-pubescente, de 60-120 cm de altura, nativa da América Tropical e propaga-se por meio de sementes. Porém, devido às características de adaptabilidade a diferentes ambientes e ao curto ciclo reprodutivo com facilidade de produção de sementes, essa espécie pode se tornar planta invasora em cultivos onde o sistema de manejo favoreça seu desenvolvimento (CONCENÇO et al., 2012).

A espécie é conhecida por criadores de animais, especialmente de algumas regiões do Sul e do Nordeste do Brasil, por ser utilizada como planta forrageira (VASCONCELOS et al., 2011) mas ainda pouco conhecida por produtores de espécies graníferas. Porém ela tem se tornado planta problemática em áreas de implantação das culturas de soja e milho em renovação e/ou desativação 
das pastagens (SILVA et al.,2018). No Estado de Mato Grosso do Sul, já foram encontradas áreas de cultivo de algodão e de soja com alta infestação dessa espécie (CONCENÇO et al., 2012).

A dormência é tida como um recurso pelo qual a natureza distribui a germinação das sementes no tempo e no espaço (CARVALHO; NAKAGAWA, 2000), sendo considerado um mecanismo de defesa das sementes contra as variações do ambiente, que dificultam ou impedem sua atividade metabólica normal (MARCOS FILHO, 2005).

As sementes viáveis e não dormentes germinam quando há disponibilidade de água, oxigênio e temperatura (FELIPPE; POLO,1983). Em plantas invasoras, diferentes componentes ambientais como temperatura e luz podem influenciar nos processos germinativos (VIVIAN et al., 2008a; YAMASHITA et al., 2009).

Os estudos direcionados sobre as exigências ambientais para germinação das sementes de espécies de plantas invasoras são de fundamental importância para o conhecimento do seu comportamento ecológico no campo, além de contribuir para desenvolvimento de estratégias para redução do banco de sementes em áreas agrícolas (SOUZA FILHO, 2006).

Nesse contexto, a presente pesquisa teve como objetivo avaliar diferentes métodos na quebra de dormência de sementes de $M$. lathyroides e a resposta germinativa dessa espécie em função de luminosidade e temperatura.

\section{Material e métodos}

Os experimentos foram conduzidos no Laboratório de Tecnologia de Sementes e Matologia (LaSeM) do CETAM (Centro de Tecnologia da Amazônia Meridional) da Universidade do Estado de Mato Grosso, Campus Universitário de Alta Floresta-MT, Brasil, no período de maio de 2013 a fevereiro de 2014.

Para estudar métodos de superação de dormência, sementes de $M$. lathyroides foram coletadas em lavouras de soja infestadas por esta planta, na região de Batayporã (MS), Brasil. O clima da região é tropical, sendo classificado por Köppen como Aw, com temperatura variando entre 14 e $32{ }^{\circ} \mathrm{C}$ e média de $22.7^{\circ} \mathrm{C}$ e $1.369 \mathrm{~mm}$ de precipitação pluviométrica média anual. $\mathrm{O}$ solo do local de coleta foi classificado como Latossolo Vermelho-escuro de textura média e com baixa fertilidade natural.

As plantas estavam se desenvolvendo naturalmente em áreas adjacentes à lavoura com cultivo de soja em sistema de semeadura direta há pelo menos duas safras. Foi realizada a coleta das sementes de pelo menos cinquenta plantas, visando permitir que a variabilidade genética natural da espécie pudesse ser mantida. Posteriormente, as sementes foram debulhadas e secadas naturalmente e reproduzidas em ambiente protegido pertencente à Universidade do Estado de Mato Grosso, Campus Universitário de Alta Floresta-MT, visando à produção e coleta de sementes para os estudos posteriores.

As sementes foram colocadas para secar em local seco e sombreado e, posteriormente, foram acondicionadas em sacos de papel e armazenadas em câmara de refrigeração a temperatura de $10{ }^{\circ} \mathrm{C}\left( \pm 2{ }^{\circ} \mathrm{C}\right)$ até seu uso.

O presente trabalho constou de duas etapas experimentais, que foram realizadas em sequência, ou seja, após a finalização da primeira etapa e com base nos dados obtidos, foi montada a segunda etapa do estudo. Para ambos os experimentos, cuja análise foi realizada em separado, foi utilizado o delineamento experimental inteiramente casualizado, com quatro repetições de 25 sementes 
para cada tratamento. Foram utilizadas caixas acrílicas do tipo gerbox $(11,0 \times 11,0 \times 3,5 \mathrm{~cm})$, submetidas a tratamento asséptico prévio através da limpeza com hipoclorito de sódio (10\%), duas horas antes da montagem dos experimentos.

1) $\mathrm{Na}$ primeira etapa, avaliaram-se 15 tratamentos químicos ou físicos promissores na superação da dormência das sementes de $M$. lathyroides, além da testemunha. Os tratamentos constituíram-se de:

- imersão em ácido sulfúrico concentrado $\left(\mathrm{H}_{2} \mathrm{SO}_{4}\right)$ por 05, 10 e 20 minutos;

- imersão em água quente a temperatura de $75^{\circ} \mathrm{C}$ por 05,10 e 15 minutos;

- escarificação com choque térmico por 05, 10 e 15 minutos;

- escarificação por ação do calor a seco a uma temperatura de $65^{\circ} \mathrm{C}$ por 02, 04 e 06 horas;

- escarificação mecânica através de fricção das sementes entre duas lixas de ferro metal restinada LFV 0046 no 120 por 01, 02 e 04 minutos;

- testemunha, onde as sementes foram colocadas diretamente para germinar.

Em seguida, todas as sementes foram submetidas à lavagem em água corrente por 05 minutos.

As sementes foram colocadas para germinar nas caixas acrílicas sobre duas folhas de papel germitest umidecidas com água destilada, na proporção de 2,5 vezes a massa do substrato seco (BRASIL, 2009) e, posteriormente, acondicionadas em câmaras de germinação tipo BOD com regime de luz de $12 \mathrm{~h}$, por meio de um conjunto de quatro lâmpadas brancas, que proporcionam aproximadamente $0,012 \mathrm{~W} \mathrm{~m}^{-2} \mathrm{~nm}^{-1}$ (CARDOSO, 1995), sendo considerada germinada a semente cuja radícula atingiu $2 \mathrm{~mm}$ de comprimento (BRASIL, 2009).

Para essa etapa experimental, foram avaliadas as seguintes variáveis: IVG (índice de velocidade de germinação) de acordo com Maguire (1962), porcentagem de germinação, comprimento médio da parte aérea e radicular das plântulas. Todos os resultados foram submetidos à análise de variância e as médias comparadas pelo teste de Tukey a 5\% de probabilidade, com auxílio do programa estatístico Sisvar (FERREIRA, 2011). A contagem do número de sementes germinadas foi realizada diariamente, por um período de dez dias (BRASIL, 2009).

2) Na segunda etapa experimental (após a determinação do melhor método para a superação da dormência das sementes de $M$. lathyroides), buscou-se avaliar o efeito da luz e da temperatura sobre a capacidade germinativa das sementes. Para o ensaio, as sementes foram submetidas à presença ou ausência de luz nas temperaturas constantes de 20, 25, $30^{\circ} \mathrm{C}$. Assim, nessa etapa, o experimento foi organizado em esquema fatorial $2 \times 3$. As sementes foram previamente escarificadas por imersão em ácido sulfúrico concentrado por 20 minutos, em seguida, submetidas à lavagem em água corrente por período de 05 minutos. Essa foi a opção do melhor tratamento de quebra de dormência, da primeira etapa experimental. Embora esse tratamento não tenha diferido do método de escarificação mecânica, optou-se por ser este, mais rápido e uniforme.

Para a condição de presença de luz, as sementes foram mantidas em câmara BOD em regime de luz de 12 horas. $\mathrm{Na}$ ausência de luz, as sementes foram mantidas no escuro durante todo o teste, envolvendo-se as caixas plásticas pretas tipo gerbox $(11,0 \times 11,0 \times 3,5 \mathrm{~cm})$ com papel alumínio e filme plástico transparente. Para avaliação na condição de ausência de luz, foi realizada a contagem do número de sementes germinadas em câmara equipada com luz verde, cujo comprimento de onda, na faixa de 610 e $650 \mathrm{~nm}$, é considerado como seguro nas avaliações de germinação em tratamentos de escuro (YAMASHITA et al., 2011). 
Foram avaliadas as seguintes variáveis: IVG (índice de velocidade de germinação) de acordo com Maguire (1962), percentual germinativo, comprimento médio da parte aérea, comprimento médio da parte radicular e peso de massa seca das plântulas. Todos os resultados obtidos foram submetidos à análise de variância e as médias comparadas pelo teste de Tukey a 5\% de probabilidade, com auxílio do programa estatístico Sisvar (FERREIRA, 2011). A contagem do número de sementes germinadas foi realizada diariamente, por um período de dez dias (BRASIL, 2009).

\section{Resultados e discussão}

Primeira etapa - estudo da quebra de dormência

Os dados dos processos germinativos de sementes de $M$. lathyroides submetidas a diferentes tratamentos de escarificação mecânica e química estão apresentados na Tabela 1 .

Tabela 1. Porcentagem de geminação, índice de velocidade de germinação (IVG) de sementes de Macroptilium lathyroides em função de diferentes processos de escarificação.

\begin{tabular}{lcc}
\hline \multicolumn{1}{c}{ Tratamentos } & Germinação (\%) & IVG \\
\hline Ácido sulfúrico 05 Minutos & $77 \mathrm{a}$ & $7,41 \mathrm{a}$ \\
Ácido sulfúrico 10 Minutos & $70 \mathrm{a}$ & $6,44 \mathrm{a}$ \\
Ácido sulfúrico 20 Minutos & $63 \mathrm{a}$ & $5,67 \mathrm{a}$ \\
Escarificação Mecânica 01 Minuto & $65 \mathrm{a}$ & $6,12 \mathrm{a}$ \\
Escarificação Mecânica 02 Minutos & $66 \mathrm{a}$ & $5,78 \mathrm{a}$ \\
Escarificação Mecânica 04 Minutos & $72 \mathrm{a}$ & $5,80 \mathrm{a}$ \\
Calor 60 ${ }^{\circ}$ C 02 Horas & $15 \mathrm{~b}$ & $0,78 \mathrm{~b}$ \\
Calor 60 ${ }^{\circ}$ C 04 Horas & $16 \mathrm{~b}$ & $0,62 \mathrm{~b}$ \\
Calor 60 ${ }^{\circ}$ C6 Horas & $17 \mathrm{~b}$ & $0,88 \mathrm{~b}$ \\
Choque térmico 05 Minutos & $10 \mathrm{~b}$ & $0,71 \mathrm{~b}$ \\
Choque térmico 10 Minutos & $09 \mathrm{~b}$ & $0,54 \mathrm{~b}$ \\
Choque térmico 20 Minutos & $14 \mathrm{~b}$ & $1,00 \mathrm{~b}$ \\
Água quente 75 ${ }^{\circ}$ C5 Minutos & $06 \mathrm{~b}$ & $0,46 \mathrm{~b}$ \\
Água quente 75 ${ }^{\circ}$ C 10 Minutos & $12 \mathrm{~b}$ & $0,66 \mathrm{~b}$ \\
Água quente 75 C 20 Minutos & $06 \mathrm{~b}$ & $0,41 \mathrm{~b}$ \\
Testemunha & $00 \mathrm{~b}$ & $0,00 \mathrm{~b}$ \\
\hline Valor de F & $56.076^{* *}$ & $45,260^{* *}$ \\
\hline DMS & 19,858 & 2,137 \\
\hline C.V. (\%) & 23,42 & 30,16 \\
\hline
\end{tabular}

**Significativo em nível de $1 \%$ de probabilidade pelo teste $F$.

Médias seguidas pela mesma letra não diferem entre si a 5\%, pelo teste de Tukey.

DMS: Diferença mínima significativa; C.V. (\%): coeficiente de variação.

Os tratamentos escarificação mecânica e escarificação química com ácido sulfúrico concentrado $\left(\mathrm{H}_{2} \mathrm{SO}_{4}\right)$ proporcionaram maior porcentagem de germinação das sementes, não havendo diferença entre si, demonstrando eficiência de ambas as metodologias, com índices de germinação entre 63\% e 77\% entre os tempos testados. Entretanto, quando as sementes foram 
submetidas aos tratamentos com água quente $75^{\circ} \mathrm{C}$, choque térmico e ação do calor a $65^{\circ} \mathrm{C}$, a germinação não atingiu 20\%. O percentual de dureza das sementes de $M$. lathyroides mostrou-se bastante elevado, pois sem tratamento para superação de dormência tegumentar, a germinação foi nula.

Esses resultados corroboram com os obtidos por Silva et al. (2012), que verificaram em ambos tratamentos a eficácia para a germinação de sementes de Mimosa caesalpiniifolia. Do mesmo modo, Carvalho e Carvalho (2009) também observaram maiores índices de geminação em sementes de Paspalum notatum, quando estas foram tratadas com ácido sulfúrico. SOUZA et al. (2010) observaram que a escarificação ácida provocou aumento da germinação e índice de velocidade de germinação em sementes da espécie invasora Sesbania virgata.

Porém FERRARESI et al. (2009) verificaram que o melhor método para superação da dormência das sementes de $M$. nudiflora foi a escarificação mecânica. Em concordância, Pinheiro (2010) obteve maiores índices de germinação para sementes de Ipomoea indivisa, I. pupurea e I. triloba através de escarificação mecânica com lixa.

Segundo Carvalho e Nakagawa (2000), diversos métodos de superação de dormência promovem a ruptura do tegumento das sementes, aumentando a permeabilidade à água e gases. Assim, promovem aumento da sensibilidade à luz e à temperatura, atuando diretamente no metabolismo e, consequentemente, sobre a germinação de sementes.

Quanto ao IVG, os mesmos tratamentos (escarificação mecânica e química com ácido sulfúrico) não apresentaram diferenças significativas entre si, indicando que a velocidade do processo germinativo das sementes de $M$. lathyroides são aumentados nestes métodos de quebra de dormência.

Constatações similares foram observadas por Erasmo et al. (2008), em sementes de Murdannia nudiflora, onde o tratamento mais favorável à superação da dormência foi escarificação mecânica e imersão das sementes em ácido sulfúrico.

Dutra et al. (2007) e Nascimento et al. (2009) trabalhando com sementes de Senna siamea e Parkia platycephala, respectivamente e concluíram que os maiores valores de germinação e IVG foram obtidos nos tratamentos com escarificação mecânica e escarificação química.

Os tratamentos usando ação do calor, choque térmico e água quente apresentaram menores porcentagens para essas variáveis. No entanto, é valido destacar que a eficiência de cada tratamento é dependente da espécie, causa e tipo de dormência tegumentar, uma vez que métodos laboratoriais de superação de dormência devem simular as condições ambientais pelas quais passam as sementes em seu "habitat" natural (GARCIA; BASEGGIO, 1999).

Os dados referentes ao desenvolvimento da parte aérea de plântulas da espécie $M$. lathyroides estão apresentados na Tabela 2. 
Tabela 2. Comprimento de parte aérea $(\mathrm{cm})$ em tratamentos para superação de dormência de sementes de Macroptilium lathyroides.

\begin{tabular}{|c|c|}
\hline Tratamentos & Parte Aérea $(\mathrm{cm})$ \\
\hline Escarificação Mecânica 04 Minutos & $64,82 \mathrm{a}$ \\
\hline Escarificação Mecânica 01 Minuto & $64,08 \mathrm{a}$ \\
\hline Escarificação Mecânica 02 Minutos & $56,50 \mathrm{ab}$ \\
\hline Ácido sulfúrico 05 Minutos & $53,68 \mathrm{ab}$ \\
\hline Ácido sulfúrico 10 Minutos & $45,81 \mathrm{abc}$ \\
\hline Ácido sulfúrico 20 Minutos & $44,75 \mathrm{abcd}$ \\
\hline Calor $60^{\circ} \mathrm{C} 06$ Horas & 37,13 bcde \\
\hline Calor $60^{\circ} \mathrm{C} 02$ Horas & 34,80 bcde \\
\hline Choque térmico 20 Minutos & 29,14 cde \\
\hline Água quente $75^{\circ} \mathrm{C} 10$ Minutos & 26,85 cde \\
\hline Calor $60^{\circ} \mathrm{C} 04$ Horas & 25,27 cde \\
\hline Choque térmico 05 Minutos & $22,59 \mathrm{def}$ \\
\hline Água quente $75^{\circ} \mathrm{C} 05^{\text {Minutos }}$ & 20,14 ef \\
\hline Água quente $75^{\circ} \mathrm{C} 20$ Minutos & $18,22 \mathrm{ef}$ \\
\hline Choque térmico 10 Minutos & 16,74 ef \\
\hline Testemunha & $0,00 \mathrm{f}$ \\
\hline Valor de F & $12,553^{* * *}$ \\
\hline DMS & 23,779 \\
\hline C.V (\%) & 25,92 \\
\hline
\end{tabular}

${ }^{* *}$ Significativo em nivel de $1 \%$ de probabilidade pelo teste $F$.

Médias seguidas pela mesma letra não diferem entre si a 5\%, pelo teste de Tukey.

DMS: Diferença mínima significativa; C.V. (\%): coeficiente de variação.

Maiores valores da parte aérea de plântulas de $M$. lathyroides foram obtidos nos tratamentos com escarificação mecânica por 04 minutos, seguido de 01 e 02 minutos de friç̧̃̃o, que não diferiram estatisticamente de ácido sulfúrico $\left(\mathrm{H}_{2} \mathrm{SO}_{4}\right)$ 10, 15 e 20 minutos. Também estes não diferiram de calor $60^{\circ} \mathrm{C}, 06$ e 02 horas respectivamente (Tabela 2).

A temperatura é um fator primário capaz de regular diretamente os processos germinativos das sementes, podendo ainda indiretamente, afetar a dormência e a viabilidade (DENG; SONG, 2012). Essa situação ocorre frequentemente com plantas invasoras, espécie rústicas que se caracterizam, sob o ponto de vista evolutivo, com uma característica adaptativa que assegura a sua sobrevivência nos diferentes ambientes agrícolas, contribuindo para a sua perpetuação. Isso tem dificultado o seu manejo ou a sua erradicação, quando necessária, culminando em inúmeros prejuízos econômicos (VIVIAN et al., 2008b).

ALENCAR et al. (2009), trabalhando com sementes de Stylosanthes macrocephala e $S$. capitata, verificaram que o uso de temperaturas elevadas propicia a superação da dormência. Resultados diferentes foram obtidos por Parreira et al. (2012), que demonstraram a ineficiência da escarificação com calor a seco para sementes de Momordica charantia.

Quanto ao comprimento de raiz (Tabela 3), maiores resultados foram observados nos tratamentos de escarificação química com ácido sulfúrico em imersão por 20 minutos, diferindo de todos os demais tratamentos testados.

Para essa variável, o tempo de exposição ao agente escarificador foi o fator que proporcionou a diferença entre os tratamentos. Em concordância, Teles et al. (2000), aplicando o tratamento 
com ácido sulfúrico entre 05, 10 e 20 minutos em sementes de Leucaena leucocephala, concluíram que o maior tempo de imersão resultou em plântulas mais vigorosas. SILVA (2013), estudando a superação da dormência de sementes de Punica granatum e Ziziphus joazeiro, encontrou maior comprimento de plântula no tratamento com ácido sulfúrico, com imersão por 20 minutos.

O estudo realizado por Almeida et al.(1979), com Macroptilium atropurpureum, em imersão por 20 minutos, concordam com os resultados obtidos no presente trabalho. A eficiência do tratamento com ácido sulfúrico é resultante da afinidade deste com água, uma vez que, quando os dois se misturam, é produzido calor excessivo, acarretando a quebra de dormência das sementes (BOTELHO et al. 2010).

Os tratamentos de exposição das sementes à água quente, choque térmico, calor e fricção por lixa provavelmente causaram danos ao embrião. Desse modo, esses tratamentos não são indicados para as sementes dessa espécie, uma vez que, segundo Marcos Filho (2005), o tratamento prégerminativo não deve prejudicar o desempenho das sementes e o desenvolvimento das plântulas.

Tabela 3. Comprimento radicular de plântulas de Macroptilium lathyroides em função da escarificação mecânica e química.

\begin{tabular}{|c|c|}
\hline Tratamentos & Parte Radicular (cm) \\
\hline Ácido sulfúrico 20 Minutos & $52,54 \mathrm{a}$ \\
\hline Escarificação Mecânica 01 Minuto & $27,20 \mathrm{~b}$ \\
\hline Escarificação Mecânica 02 Minutos & $21,26 \mathrm{bc}$ \\
\hline Escarificação Mecânica 04 Minutos & $17,13 \mathrm{bcd}$ \\
\hline Calor $60^{\circ} \mathrm{C} 02$ Horas & $16,15 \mathrm{bcd}$ \\
\hline Ácido sulfúrico 05 Minutos & $15,89 \mathrm{bcd}$ \\
\hline Ácido sulfúrico 10 Minutos & $14,89 \mathrm{bcd}$ \\
\hline Calor 60 C 06 Horas & $14,55 \mathrm{~cd}$ \\
\hline Calor $60^{\circ} \mathrm{C} 04$ Horas & $13,17 \mathrm{~cd}$ \\
\hline Choque térmico 20 Minutos & $13,14 \mathrm{~cd}$ \\
\hline Agua quente $75^{\circ} \mathrm{C} 10$ Minutos & 12,62 cde \\
\hline Choque térmico 05 Minutos & 12,49 cde \\
\hline Agua quente $75^{\circ} \mathrm{C} 05$ Minutos & 9,96 cde \\
\hline Agua quente $75^{\circ} \mathrm{C} 20$ Minutos & $8,27 \mathrm{de}$ \\
\hline Choque térmico 10 Minutos & $8,16 \mathrm{de}$ \\
\hline Testemunha & $0,00 \mathrm{e}$ \\
\hline Valor de F & $18,342^{* *}$ \\
\hline DMS & 12,936 \\
\hline C.V (\%) & 30,70 \\
\hline
\end{tabular}

${ }^{*}$ Significativo em nivel de $1 \%$ de probabilidade pelo teste $F$.

Médias seguidas pela mesma letra não diferem entre si a $5 \%$, pelo teste de Tukey.

DMS: Diferença mínima significativa; C.V. (\%): coeficiente de variação.

$\underline{\text { Segunda etapa - estudo da resposta à temperatura e luminosidade }}$

Com base nos resultados anteriores, procedeu-se à escarificação química das sementes de $M$. lathyroides que, posteriormente foram colocadas para germinar sob diferentes temperaturas e luminosidade. Os resultados referentes à capacidade germinativa das sementes, submetidas a diferentes temperaturas na presença e na ausência de luz, estão apresentados na Tabela 4. Não houve diferença significativa tanto para os fatores isolados (temperaturas e luminosidade) como para a interação entre eles para germinação e IVG. Para comprimento da parte aérea, houve 
significância para os fatores isoladamente. Somente para o comprimento do sistema radicular e massa seca de plântulas foi verificada interação significativa entre os fatores.

Tabela 4. Porcentagem de geminação, índice de velocidade de germinação (IVG) e comprimento da parte aérea $(\mathrm{cm})$ de Macroptilium lathyroides submetidas a diferentes temperaturas na presença e ausência de luz.

\begin{tabular}{lcccc}
\hline Fator & Condição & Germinação (\%) & IVG (\%) & Parte Aérea (cm) \\
\hline \multirow{2}{*}{ Luz } & Ausência & $69,01 \mathrm{a}$ & $7,37 \mathrm{a}$ & $87,68 \mathrm{a}$ \\
& Presença & $69,45 \mathrm{a}$ & $7,91 \mathrm{a}$ & $53,06 \mathrm{~b}$ \\
\hline \multirow{2}{*}{ Temperatura $\left({ }^{\circ} \mathrm{C}\right)$} & 20 & $72,50 \mathrm{a}$ & $6,96 \mathrm{a}$ & $65,30 \mathrm{~b}$ \\
& 25 & $66,01 \mathrm{a}$ & $7,80 \mathrm{a}$ & $75,15 \mathrm{a}$ \\
& 30 & $69,14 \mathrm{a}$ & $8,25 \mathrm{a}$ & $68,24 \mathrm{ab}$ \\
\hline CV (\%) & & 14,07 & 16,47 & 7,64 \\
\hline
\end{tabular}

${ }^{*}$ Médias seguidas de mesma letra, em cada coluna, não diferem entre si, pelo teste de Tukey, a 5\% de probabilidade.

Quanto à variável porcentagem de germinação e IVG, observa-se que não houve efeito significativo entre os fatores analisados. Em relação à resposta à luz, as sementes são classificadas em três grandes grupos: fotoblásticas positivas (germinam com luz), fotoblásticas negativas (não germina com luz) e ocorrem também aquelas que apresentam um comportamento indiferente ou insensível à luz são não-fotoblásticas ou neutras (BEWLEY; BLACK, 1994). Dentro desta classificação, os autores KLEIN; FELIPPE (1991) denominaram o caráter fotoblástico positivo de "preferencial" quando alguma germinação ocorre na ausência de luz e de "absoluto" quando a germinação é totalmente nula na ausência de luz. A espécie em estudo, de acordo com a classificação citada, comportou-se como fotoblásticas positiva "preferencial".

Do mesmo modo, Salvador (2007), trabalhando com cinco espécies invasoras Euphorbia heterophylla, Eleusine indica, Ipomoea nil, Sida glaziovii e Braquiaria plantaginea, em condições de temperaturas alternadas entre 20 e $30^{\circ} \mathrm{C}$, concluíram que todas as espécies testadas respondem de forma indiferente à luz. De acordo com Souza et al. (2010), a não influência da luz sobre os processos germinativos de algumas espécies invasoras, indicam uma estratégia em ocupar outros nichos ou formar populações adensadas, visto que seus propágulos podem germinar até mesmo em condições de baixa temperatura. Em concordância, Walters (2009) e Searle (2011) afirmam que a maioria das espécies vegetais tem capacidade de aclimatar-se a determinadas variações de temperatura e luminosidade. Aparentemente, a germinação das sementes de $M$. lathyroides, pode ocorrer normalmente em temperaturas entre $20^{\circ} \mathrm{C}$ e $30^{\circ} \mathrm{C}$, o que revela seu potencial de infestação em ambientes com grandes amplitudes térmicas e de luminosidade.

Para comprimento de parte aérea, verificou-se que as condições de regimes de temperatura de 25 e $30^{\circ} \mathrm{C}$ foram as que proporcionaram maiores valores, não diferindo, entretanto de 20 'C (Tabela 4). Para essa variável, ao se compararem resultados obtidos sob ausência e presença de luminosidade, constatou-se efeito positivo da ausência de luz. Para Kendrick e Kronenberg (1994), as sementes pequenas possuem pouca quantidade de reserva energética e, geralmente, precisam germinar mais rapidamente em busca de luz para realizar seus processos fotossintéticos e se tornarem planta autotrófica. Deste modo, justifica-se o alongamento do caule da espécie, em estudo em ambiente com ausência de luminosidade. 
Quanto, ao comprimento radicular das plântulas de $M$. lathyroides (Tabela 5), verifica-se que esta variável foi influenciada pela temperatura e pela luminosidade com interação entre estes dois fatores $(p<0,05)$. O comprimento da raiz na presença de luz e sob $20^{\circ} \mathrm{C}$ foi a condição que proporcionou maior comprimento radicular das plântulas, apresentando média de $26,09 \mathrm{~cm}$. Nas demais condições, o comprimento da raiz não atingiu $15 \mathrm{~cm}$. Na condição de ausência de luz, o maior comprimento radicular foi de $12,73 \mathrm{~cm}$ sob $20^{\circ} \mathrm{C}$, não diferindo dos outros tratamentos térmicos.

\section{Tabela 5. Comprimento radicular $(\mathrm{cm})$ de plântulas de Macroptilium lathyroides submetidas a diferentes temperaturas em presença e ausência de luz.}

\begin{tabular}{ccc}
\hline \multirow{2}{*}{ Temperaturas $\left({ }^{\circ} \mathbf{C}\right)$} & \multicolumn{2}{c}{ Ambiente } \\
\cline { 2 - 3 } & Presença de luz & Ausência de luz \\
\hline 20 & $26,09 \mathrm{Aa}$ & $12,73 \mathrm{Ab}$ \\
25 & $12,65 \mathrm{Ba}$ & $12,02 \mathrm{Aa}$ \\
30 & $10,84 \mathrm{Ba}$ & $10,11 \mathrm{Aa}$ \\
\hline
\end{tabular}

C.V. (\%)

21,11

Médias seguidas de mesma letra maiúscula nas colunas, e minúscula nas linhas, não diferem entre si pelo teste de Tukey a $5 \%$ de probabilidade.

Santos e Zonetti (2009) relatam que o aumento gradativo da temperatura afeta a disponibilidade hídrica, influenciando significativamente no desenvolvimento da plântula.

A luz é um fator necessário para germinação de grande número de sementes de espécies daninhas (RADOSEVICH et al., 1997), como verificado por Yamashita et al. (2009) em Chaptalia nutans; Yamashita et al. (2009), com Emilia sonchifolia e Maia et al. (2008) em sementes de Hyptis suaveolens. Entretanto, para algumas espécies, como é o caso da M. lathroides, a germinação ocorreu mesmo na ausência de luz.

A ação da luz nos vegetais está ligada à ativação do fitocromo, que desencadeia alterações nas vias metabólicas e no funcionamento das membranas celulares, mudando a permeabilidade e alterando o fluxo das substâncias celulares (HILHORST; KARSSEN, 1988). Quando são fornecidas condições ideais à germinação, as sementes se tornam mais vigorosas e, consequentemente, originam plântulas com maior taxa de crescimento, em função da maior capacidade de transformação e suprimento de reservas dos tecidos de armazenamento e maior incorporação destes pelo eixo embrionário (DAN et al.,1987; NAKAGAWA, 1999).

Os resultados referentes ao peso de massa seca (Tabela 6) indicam que houve influência da interação dos fatores temperatura e luminosidade. O maior acúmulo de matéria seca ocorreu quando as sementes foram submetidas à temperatura de $20^{\circ} \mathrm{C}$, tanto na presença como em ausência de luz, diferindo significativamente de 25 e $30^{\circ} \mathrm{C}$. Verificou-se, também, que, em $20^{\circ} \mathrm{C}$, na presença de luz, a resposta para a variável massa seca foi maior, seguida de 25 e $30^{\circ} \mathrm{C}$. 
Tabela 6. Peso de massa seca (g) de plântulas de Macroptilium lathyroides submetidas a diferentes temperaturas na presença e na ausência de luz.

\begin{tabular}{ccc}
\hline Temperaturas $\left({ }^{\circ} \mathbf{C}\right)$ & \multicolumn{2}{c}{ Ambiente } \\
\cline { 2 - 3 } & Presenca de luz & Ausência de luz \\
20 & $0,00340 \mathrm{Aa}$ & $0,00160 \mathrm{Ab}$ \\
25 & $0,00081 \mathrm{Ba}$ & $0,00037 \mathrm{Bb}$ \\
30 & $0,00051 \mathrm{Ca}$ & $0,00014 \mathrm{Cb}$
\end{tabular}

$\mathrm{CV}(\%)$

9,94

Médias seguidas de mesma letra maiúscula, nas colunas, e minúscula, nas linhas, não diferem entre si pelo teste de Tukey a $5 \%$ de probabilidade.

Semelhantemente, Stefanello et al. (2006) relataram maior acúmulo de fitomassa seca para sementes de Hipericum brasiliense nas mesmas condições de luminosidade e temperatura.

Diante dos resultados verifica-se que, apesar de a espécie ter se comportado como indiferente às condições de luminosidade para seus processos germinativos iniciais, o comprimento radicular e massa seca obtiveram maiores médias na presença de luz. Esses resultados evidenciam que a ocorrência de $M$. lathyroides em ambientes cultivados, pode ser controlada por meio da aplicação de práticas de manejo que promovam a manutenção das sementes enterradas ou cobertas por palhada.

\section{Conclusões}

A escarificação química pela imersão em ácido sulfúrico durante 20 minutos e a mecânica com lixa no 120 durante 01,02 e 04 minutos foram os métodos mais eficientes. A espécie é classificada como fotoblástica "preferencial" e a germinação responde positivamente a todas as temperaturas testadas.

\section{Agradecimentos}

À FAPEMAT - Fundação de Amparo á Pesquisa do Mato Grosso, pelo financiamento do projeto de pesquisa.

\section{Referências}

ALENCAR, K.M. DE C.; LAURA, V.A.; RODRIGUES, A.P.A.C.; RESENDE, R. M. S. Tratamento térmico para superação da dormência em sementes de Stylosanthes SW. (Fabaceae Papilionoideae). Revista Brasileira de Sementes, Londrina, v.31, n.2, p. 164-170, 2009.

ALMEIDA, L. D'A.; MAEDA, A.J; FALIVENE, S.M.P. Efeitos de métodos de escarificação na germinação de sementes de cinco leguminosas forrageiras. Bragantia, Campinas, v.38, n.9, p. 84-96, 1979.

BEWLEY, J.D.; BLACK, M. Seeds: physiology of development and germination. 2. 
ed. New York: Plenum, 1994. 445p.

BOTELHO, A.V.F.; BARBOSA, U.N.; SANTOS, W.B.; PASSOS, M.A.A. Avaliação de diferentes métodos de superação de dormência em sementes de braúna (Schinopsis brasiliensis Eng1.). In: X Jornada de Ensino, Pesquisa e Extensão - JEPEX, 2010, Recife. Anais... Recife: UFRPE, 2010.

BRASIL. Ministério da Agricultura e Reforma Agrária. Regras para Análise de Sementes. Brasília: SAND/DNDV/CLAV, 2009.365p.

CARVALHO, N.M.; NAKAGAWA, J. Sementes: ciência, tecnologia e produção. 4 ed. Jaboticabal: FUNEP, 2000. 588p.

CARVALHO, r.N.; CARVALHO, D.B. Germinação de sementes de um ecótipo de paspalum da região de Guarapuava PR. Semina: Ciências Agrárias, Londrina, v. 30, suplemento 1, p. 1187-1194, 2009.

CARDOSO, V.J.M. Germinação e fotoblastismo de sementes de Cucumis anguria: influência da qualidade da luz durante a maturação e secagem. Revista Brasileira Fisiologia Vegetal, São Paulo, v. 7, n. 1, p. 75-80, 1995.

CONCENÇO, G.; ANDRES, A.; GALON, L.; PONTES, C.S.; CORREIA, V.T. Controle de Macroptilium lathyroides com herbicidas aplicados em pré e pós-emergência. Revista Brasileira de Herbicidas, Umuarama, v.11, n.1, p.11-23, 2012.

DAN,E.L.; MELLO, V.D.C.;WETZEL, C.T.Transferência de matéria seca como modo de avaliação do vigor de sementes de soja. Revista Brasileira de Sementes, Londrina, v. 9, n. 3, p. 45-55, 1987.

DENG, Z.; SONG, S. Sodium nitroprusside, ferricyanide, nitrite and nitrate decrease the thermo-dormancy of lettuce seed germination in a nitric oxide-dependent manner in light. South African Journal of Botany, Scottsville, v. 78, p. 139-146, 2012.

DUTRA, A.S.; FILHO, S.M.; TEÓFILO, E.M.; DINIZ, F.O. Germinação de sementes de Senna siamea (lam.) H.S. Irwin e Barneby - Caesalpinoideae. Revista Brasileira Sementes, Londrina, v. 29, n. 1, p. 160-164, 2007.

ERASMO, E.A.L.; TERRA, M.A.; COSTA, N.V.; DOMINGOS, V.D.; DIDONET, J. Fenologia e acúmulo de matéria seca em plantas de Murdannia nudiflora durante seu ciclo de vida. Planta Daninha, Viçosa, v.21, n.3, p.397-402, 2003.

FELIPPE, G.M.; POLO, M. Germinação de ervas invasora: efeito de luz e escarificação. Revista Brasileira de Botânica, São Paulo, v. 6, n. 1, p. 55-60, 1983.

FERREIRA,D. F. Sisvar: a computer statistical analysis system. Ciência e Agrotecnologia, 
Lavras, v. 35, n.6, p. 1039-1042, 2011.

FERRARESI, D. A.; YAMASHITA, O. M.; CARVALHO, M. A.C. Superação da dormência e qualidade de luz na germinação de sementes de Murdannia nudiflora (L.) Brenans. Revista Brasileira de Sementes, Londrina, v. 31, n. 4, p.126-132, 2009.

GARCIA, E.N.; BASEGGIO,J. Poder germinativo de sementes de Desmodium incanum DC. (Leguminosae). Revista Brasileira de Agrociência, Pelotas, v. 5, n. 3, p. 199-202, 1999.

HILHORST, H.W.M.; KARSSEN, C.M. Dual effects of light on the gibberellin and nitrate stimulated seed germination of Sisymbrium officinale and Arabidopsis thaliana. Plant Physiology, Lancaster , v. 86, n. 2, p. 591-597, 1988.

HOFFMANN, A. Apresentação. In: VARGAS, L.; ROMAN, E. S. (Ed.) Manual de manejo e controle de plantas daninhas. Bento Gonçalves: Embrapa Uva e Vinho, 2004. p.5.

KENDRICK, R.E.; KRONENBERG, G.H.M. Photomorphogenesis in plants. 2nd ed. Dordrecht: Academic Publishers, 1994. 828p.

KLEIN, A.; FELIPPE, G. M. Efeito da luz na germinação de sementes de ervas invasoras. Pesquisa Agropecuária Brasileira, v.7, n.26, p.955-966, 1991.

LORENZI, H. Plantas daninhas do Brasil: terrestres aquáticas, parasitas e tóxicas. 3. ed. Nova Odessa, SP: Instituto Plantarum, 2000. 608p.

MAIA, S.S.S.; PINTO, J.E.B.; OLIVEIRA, J.A.; SILVA, F. N.; SANTOS,F.M. Germinação de sementes de Hyptis suaveolens (L.) Poit. (Lamiaceae) em função da luz e da temperatura. Revista Caatinga, Mossoró, v. 21, n.4, p.212-218, 2008.

MAGUIRE, J. D. Speed of germination-aid in selection and evaluation for seedling emergence and vigour. Crop Science, London, v. 2, n. 2, p. 176-177, 1962.

MARCOS FILHO,J. Fisiologia de sementes de plantas cultivadas. Piracicaba: FEALQ, 2005. 495p.

NAKAGAWA, J. Testes de vigor baseados no desempenho de plântulas. In: KRZYZANOWSKI, F.C., VIEIRA, R.D.; FRANÇA NETO, J.B. Vigor de sementes: conceitos e testes. Londrina: ABRATES, Comitê de Vigor de Sementes. 1999. 218p.

NASCIMENTO, I. L.; ALVES, E. U.; BRUNO, R. L. A.; GONÇALVES, E. P.; COLARES, P. N. Q.; MEDEIROS, M. S. Superação da dormência em sementes de faveira (Parkia platycephala Benth.). Revista Árvore, Viçosa, v.33, n.1, p.35-45, 2009.

PARREIRA, M.C.; CARDOZO, N; PEREIRA, F.C. M.; ALVES, P.L.C.A.; Superação 
de dormência das sementes e controle químico de Momordica charantia L. Bioscience Journal, Uberlândia, v. 28, n. 3, p. 358-365, 2012.

PINHEIRO, R.T. Superação de dormência das sementes e controle químico de cordade-viola (Ipomoea spp.) em soja resistente ao glifosato. 2010.73f. Dissertação (Mestrado em Agronomia) - Universidade Federal de Santa Maria, RS.

RADOSEVICH, S., HOLT, J., GHERSA, C.W. Weed ecology: implications for management. New York: John Willey, 1997. 589p.

RODRIGUES, B.N.; PITELLI, R.A. Quebra de dormência em sementes de Commelina benghalensis. Planta Daninha, Viçosa, v.12, n.2, p.106-110, 1994.

SALVADOR, F.L. Germinação e emergência de plantas daninhas em função da luz e da palhada de cana-de açúcar (Saccharum spp). 2007. 84f. Dissertação (Mestrado em Agronomia) - Universidade de São Paulo, Piracicaba, SP.

SANTOS, G.A.; ZONETTI, P.C. Influência da temperatura na germinação e desenvolvimento do girassol (Helianthus annuus L.) Iniciação Científica CESUMAR, Maringá, v. 11, n. 1, p. 23-27, 2009.

SILVA, L.M.M. Protocolos de criopreservação de sementes de romã e juá. 2013. $160 f$. Dissertação (Mestrado em Engenharia Agrícola) - Universidade Federal de Campina Grande, PB.

SILVA, M.L.; FREITAS, R.M.O.; NETO, J.A.R.; DOMBROSKI, J.L.D.; FARIAS, R.M.Emergência e desenvolvimento inicial de plântulas de Mimosa caesalpiniifolia Benth. Revista Verde, Mossoró, v. 7, n. 3, p. 199-204, 2012.

SILVA, M.S.A.; YAMASHITA, O.M.; ROSSI, A.A.B., CONCENÇO, G.; CARVALHO, M.A.C.; FELITO, R.A. Cytotoxic and genotoxic effects of Macroptilium lathyroides. Planta Daninha, Viçosa, v36:e018166574, 2018. DOI: 10.1590/S010083582018360100043.

SOUZA FILHO, A.P.S. Interferência potencialmente alelopática do capim-gengibre (Paspalum maritimum) em áreas de pastagens cultivadas. Planta Daninha, Viçosa, v.24, n.3, p.451-456, 2006.

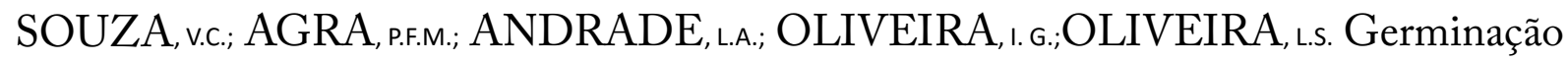
de sementes da invasora Sesbania virgata (Cav.) Pers. sob efeito de luz, temperatura e superação de dormência. Semina: Ciências Agrárias, Londrina, v. 31, n. 4, p. 889-894, 2010.

SEARLE S.Y.;THOMAS, S.;GRIFFIN, K.L.; HORTON, T.;KORNFELD,A.; YAKIR,D.,HURRY, V.; TURNBULL,M.H. Leaf respiration and alternative oxidase 
in field-grown alpine grasses respond to natural changes in temperature and light. New Phytologist, Norwich, v.189, p.1027-1039, 2011.

STEFANELLO, R.; GARCIA,D.C.; MENEZES, N.L.; WRASSE, C.F.; Influência da luz, temperatura e estresse hídrico na germinação e no vigor de sementes de anis. Revista Brasileira de Agrociência, Porto Alegre, v. 12, n. 1, p. 45-50, 2006.

TELES, M.M.; ALVES, A.A.; OLIVEIRA,J.C.G.; BEZERRA, A.M.E. Métodos para Quebra da dormência em sementes de leucena (Leucaena leucocephala (Lam.) de Wit. Revista Brasileira de Zootecnia, Brasília, v. 29, n.2, p.387-391, 2000.

VASCONCELOS, W.A.; SANTOS, E.M.; ANDRADE, A.P.; BRUNO, R.L.A.; EDVAN, R.L. Germinação de sementes e desenvolvimento de plântulas de figo de pombo (Macroptilium lathyroides). Revista Trópica, São Luiz, v.5, n.1, p.3-11, 2011.

VIVIAN, R.; GOMES JR., F.G.; CHAMMA, H.M.C.P.; SILVA, A.A.; FAGAN, E.B.; RUIZ, S.T. Efeito da luz e da temperatura na germinação de Alternanthera tenella, Conyza bonariensis e Digitaria ciliaris. Planta Daninha, Viçosa, v.26, n.3, p.507-513, 2008a.

VIVIAN, R.; SILVA, A.A.; GIMENES,JR., M.; FAGAN, E.B.; RUIZ, S.T.; LABONIA, V.Dormência em sementes de plantas daninhas como mecanismo de sobrevivência - Breve revisão. Planta Daninha, Viçosa, v.26, n.3, p. 695-706, 2008b.

WALTER, A.; SILK W.K.; SCHURR, U. Environmental effects on spatial and temporal patterns of leaf and root growth. Annual Review of Plant Biology, Stanford, v.60, p. 279-304, 2009.

YAMASHITA, O.M.; GUIMARÃES, S.C.; CAVENAGHI, A.L. Germinação das sementes de Conyza canadensis e Conyza bonariensis em função da qualidade de luz. Planta Daninha,Viçosa, v. 29, n. 4, p. 737-743, 2011.

YAMASHITA, O.M.; GUIMARÃES, S.C.; ALBUQUERQUE,M.C.F.; CARVALHO, M.A.C.; SILVA; J.L. efeitos de fatores ambientais induzidos na germinação de sementes de Chaptalia nutans (L.) Polack. Revista Brasileira de Sementes, Londrina, v. 31, n. 3, p.132-139, 2009.

YAMASHITA, O.M.; GUIMARÃES, S.C.; SILVA, J.L.; CARVALHO, M.A.C.; CAMARGO, M.F. Fatores ambientais sobre a germinação de Emilia sonchifolia. Planta Daninha,Viçosa, v.27, n.4, p.673-681, 2009. 